Pro-Criminal Attitudes, Intervention, and Recidivism

\author{
Rainer Banse ${ }^{1,2}$, Judith Koppehele-Gossel ${ }^{1,2}$, Lisa M. Kistemaker ${ }^{1,2}$, \\ Verena A. Werner ${ }^{1,2}$ \& Alexander F. Schmidt ${ }^{1}$ \\ ${ }^{1}$ University of Bonn \\ ${ }^{2}$ Bonner Institut für Rechts- und Verkehrspsychologie
}

Accepted for publication in Aggression and Violent Behavior (2013)

\begin{abstract}
Author Note
Correspondence concerning this article should be addressed to Rainer Banse, Department of Psychology, Social \& Legal Psychology, University of Bonn, KaiserKarl-Ring 9, 53111 Bonn, Germany. Email: banse@uni-bonn.de.
\end{abstract}




\begin{abstract}
We review the recent research literature on pro-criminal attitudes (PCAs) as a causal factor of recidivism with a focus on studies on the effectiveness of offender treatment programs targeting PCAs to prevent recidivism. The main conclusions that can be derived from the literature are: (1) the evidence supports the hypothesis that PCAs are related to reoffending; (2) most investigated offender treatment programs tend to reduce PCAs, although the general lack of adequate control group designs does not rule out alternative explanations for this reduction; and (3) there is no conclusive empirical evidence that intervention programs designed to reduce PCAs are effective in reducing recidivism. Empirical research in this area lacks the theoretical and methodological rigor to test causal models of the influence of treatment on reducing PCAs, and effects of PCAs on recidivism. Limitations of the empirical evidence are related to inadequate research designs and/or suboptimal data analysis strategies. Recommendations concerning optimized research designs and data analysis strategies that are likely to provide more conclusive evidence on the relation of PCAs, PCA treatment, and recidivism are given.
\end{abstract}

Key words: pro-criminal attitudes, offence-supportive beliefs, intervention, recidivism, reoffending 


\section{Pro-Criminal Attitudes, Intervention, and Recidivism}

Crime-supportive or pro-criminal attitudes (PCAs) figure prominently among the "Big Four" criminogenic needs in Andrews and Bonta`s (2010) Risk-Need-Responsivity Model of offender rehabilitation. In meta-analyses, it has been consistently shown that general (Andrews \& Bonta, 2010) or offencs-specific (Helmus, Hanson, Babchishin, \& Mann, 2013) PCAs are empirically related to recidivism with small to moderate effect sizes. Theoretically, in criminology, Sykes and Matza's (1957) Neutralization Theory postulates that PCAs (i.e., rationalizations, justifications) precede and cause criminal behavior. To overcome the barriers erected by socialization and to violate the law it is a necessary condition to find reasons or excuses or to claim special circumstances that justify illegal behavior. From a psychological perspective, it seems more plausible that the need for PCAs arises as a consequence of and not as a cause for criminal behavior. From Festinger's (1957) theory of cognitive dissonance, one can derive, accordingly, the prediction that contradictions between illegal behavior and the individuals' knowledge of, and adherence to, societal norms elicit an unpleasant state of cognitive dissonance that can be reduced by adding pro-criminal cognitions. However, this "hen-and-egg" question is mainly of academic relevance. From either perspective one would expect that PCAs, once established, lower the threshold to commit criminal offences in the future. A reduction of PCAs should therefore reduce the risk of criminal behavior. Moreover, attitudes are only moderately stable and can be changed by appropriate measures of education, training, or therapy. Consequently, PCAs are considered to be a dynamic risk factor that can be reduced or eliminated by dedicated modules in offender treatment programs. In the following sections we will review the empirical support for 
the assumptions that offender treatment programs can reduce PCAs, and that this reduction is conducive to offender rehabilitation.

Although these assumptions about PCAs are widely accepted in criminology and forensic psychology, they can be criticized. For example, the unpleasant contradiction between one's own criminal behavior and the knowledge of accepted societal norms is expected to be maximal in individuals who are involved in a criminal subculture and "normal" civil life at the same time. Offenders who are exclusively immersed in a criminal subculture, and have few ties to legal life, may not need to develop PCAs to justify their behavior. It seems, therefore, plausible that some of the most prolific offenders hold relatively little PCAs as compared to "average" offenders. Counterintuitively, if offender treatment successfully induces a more positive evaluation of societal norms, the law, and law enforcement institutions, this change may increase cognitive dissonance, and, thus in turn, amplify PCAs to reduce dissonance. It is, therefore, conceivable that successful offender treatment leads to a paradoxical increase of PCAs at least in some offenders.

Another critical argument revolves around the question whether reducing PCAs is unconditionally helpful in preventing crime. In an extensive theoretical analysis, Maruna and Copes (2005) and Maruna and Mann (2006) have cogently argued that the common rationale and some of the corresponding interventions used in offender treatment programs may be counterproductive. For example, the aim that offenders take full and unconditional personal responsibility for their criminal acts (instead of minimizing their responsibility) implies the construction of a genuinely criminal self-concept, the belief to be a fundamentally bad and unworthy person who does bad things. This kind of selfconcept may be realistic, but does not necessarily enhance adjustment. These partially 
realistic negative self-concepts are typical for people suffering from depression (Ware \& Mann, 2012). Desistance research (Maruna, 2001) has revealed that criminals who desist from crime manage to maintain a positive self-concept while finding new ways to ascribe sense and meaning to their lives without committing crimes. These empirical findings suggest that any intervention to reduce PCAs should avoid creating a dysfunctional identity (i.e., condemnation script; Maruna, 2001) that undermines offenders' self-esteem and their ability to actively change their lifestyle.

\section{Literature Review}

Even though it is widely accepted that PCAs increase the risk of criminal behavior (Andrews \& Bonta, 2010) this relationship may vary across different types of offenders and different types of PCAs. Although a reduction of PCAs in offenders should be generally conducive to prevent future crimes, interventions could also have unwanted iatrogenic side effects. It seems, therefore, premature to assume that any reduction of PCAs automatically reduces recidivism. For an evidence-based commissioning strategy of offender treatment programs it seems therefore critical to evaluate the empirical evidence on PCA-effects with regard to three questions: (1) How strong is the causal relationship between PCAs and subsequent criminal behavior? (2) What interventions have been shown to effectively reduce PCAs? and (3) How effective are those treatments to reduce recidivism?

A path model (Figure 1) illustrates the presumed causal relationships between PCAs, intervention, and criminal behavior or recidivism. If there is substantial evidence that offending and PCAs are positively correlated, this correlation does not allow to distinguish between Path A (PCAs cause offending) and Path B (offending causes PCAs). However, both are not mutually exclusive and it is plausible that PCAs and offending do 
reinforce and maintain each other in a positive feedback loop. For the purposes of offender treatment and rehabilitation, it is critical whether PCAs predict future offending. In order to empirically confirm the effectiveness of PCA intervention programs it is necessary to show (1) that an intervention significantly reduces PCAs (Path D), and (2) that this change would not have occurred without the intervention (Path C). The second condition is not trivial: PCAs may be reduced by the conviction or detention as such or simply through aging of the offender during incarceration. In order to empirically demonstrate that an intervention has caused the effect, it is imperative to employ a control group design to test Path D against Path C.

(insert Figure 1 about here)

Many intervention programs (e.g., Sex Offender Treatment Programme [SOTP]; Beech, Oliver, Fisher, \& Beckett, 2005) use multiple modules targeting different criminogenic needs of offenders. The empirical demonstration that an intervention does reduce PCAs (as compared to no intervention) does not imply that the modules intended to reduce PCAs have caused the effect. In order to empirically establish the causal role of specific elements of a program, it is necessary to run the program with and without the dedicated PCA modules, contrasting Paths D and E. Finally, PCA intervention programs are only worthwhile if the reduction of PCAs also leads to a reduction in recidivism (Path $\mathrm{G}$ ). It could well be that the program only teaches offenders to pretend reduced PCAs (because they want to be good program graduates, or expect imprisonment-related advantages such as more positive evaluations, earlier release, and/or positioning in less controlled settings). The finding that the participation in the program reduces recidivism may also be due to the effective reduction of other criminogenic needs that are unrelated to PCAs (Path E). 
In summary, for a conclusive empirical demonstration of the effectiveness of a PCA intervention program, it is necessary to show that the program reduces PCAs (Path D) as compared to a relevant control condition (Path C), and that the reduction of PCAs mediates the reduction of recidivism (Path G) as compared to program effects on other criminogenic needs (Path E). The existing empirical evidence will be evaluated in light of this causal model.

\subsection{Measures of pro-criminal attitudes and offending}

In social psychology, attitudes are defined as "a psychological tendency that is expressed by evaluating a particular entity with some degree of favor or disfavor" (Eagly

\& Chaiken, 1993, p. 1). In more than 60 years of research on PCAs, a considerable number of measures have been developed. They range from qualitative structured or semi-structured interview approaches to quantitative standardized questionnaire measures. A detailed review of the construct domain is beyond the scope of this report. Given that the main focus of this review is on changing PCAs to reduce recidivism, we will only briefly introduce the measures that were actually used in intervention research of the last 15 years. Andrews and Bonta (2010) have proposed a classification of PCA measures to structure the construct domain. According to the authors most PCA measures belong to one of three classes: 1) Techniques of Neutralization, 2) Identification with criminal others, 3) Rejection of convention.

From a theoretical perspective, these three classes appear reasonably distinct at the conceptual level, and they identify three different psychological functions of PCAs. Techniques of neutralization arise from the need to justify one's own criminal behavior in light of contrasting social, moral, and legal norms. They may alleviate the felt conflict between ought and actual behavior and hence constitute a maintaining factor of 
delinquency. Identification with criminal others highlights the admiration and imitation of criminal models, as well as the importance of social and personal relationships in criminal subcultures. Rejection of convention comprises attitudes that emphasize opposition to the legal system and its agents such as the police, and courts. Moreover, beyond devaluing socially accepted values, these attitudes glorify the socially antagonistic and illegal behavior and lead to an unconventional, rebellious, interesting, or even heroic criminal identity. Such an identity may be functional to satisfy the needs of high self-esteem, a positive identity and also the need for uniqueness.

\subsubsection{General pro-criminal attitudes}

Prototypically, the validity of most PCA-scales has been established by relating them to prior or later self-reported criminal behavior or offenses. For example, Walters (2005) reports the results of six studies that relate the eight subscales of his Psychological Inventory of Criminal Thinking Styles (PICTS) to disciplinary measures in prison or recidivism. The average effect size $(r)$ in predicting these criteria ranges between .10 and .15 across the eight subscales. Walters (2011) also demonstrated that the PICTS total score has a predictive validity of about $r=.20$. The total score has been shown to predict recidivism above and beyond other known risk factors such as age, prior convictions, prior incident reports and the self report on lifestyle criminality.

Similar evidence exists for different versions of the Criminal Sentiments Scale (CSS; Gendreau, Grant, Leipciger, \& Collins, 1979), the Criminal Sentiments Scale Modified (CSS-M, Simourd, \& van de Ven, 1999), and a newer version of the CSS-M (Simourd, \& Olver, 2002). In the latter study, predictive validity was investigated using a sample of 207 offenders with a relatively short time at risk of less than a year $(M=266$ days, $S D=$ 274). The four subscales General Criminal Sentiments, Adversarial Law Beliefs, Criminal 
Subculture Beliefs, and Criminal Self-Concept predicted one or more different measures of reoffending (rearrest, violent rearrest, reconviction, and reincarceration) with correlations ranging from .00 to .24; nine out of 16 correlations were significant with a median correlation of .18. Notably, the subscales tended to correlate stronger with indicators of future than with past offending behavior.

Table 1 presents all PCA measures that were used in the studies reviewed in this report. The table also contains information on the reliability of all scales and subscales. The reliabilities of the different PCA scales are in general satisfactory, with the exception of some subscales in multi-scale measures. It has to be noted that insufficient scale reliability limits the chances to find (valid) correlations with other variables such as recidivism. In consequence, the predictive validity of aggregated total scores are expected to be higher than those of less reliable subscales. Given the generally weak effect sizes in predicting recidivism, it is particularly important that reliable scales are used to discover existing relations between PCAs and criminal behavior.

(insert Table 1 about here)

In summary, standard measures of PCAs tend to have reasonable psychometric properties and are related to past and future criminal behavior. Significant correlations are normally found only for some subscales and some indices of criminal behavior. Effect sizes between PCAs and recidivism rarely exceed the level of $r=.25$. However, criterion measures of reoffending often lack reliability and validity due to the dunkelfeld problem, sample attrition due to death, relocation, or change of name of offenders, and delayed, incomplete or erroneous entries in national offence registries.

The social psychological literature on the attitude-behavior (in-)consistency (e.g., Eagly \& Chaiken, 1993) has identified additional moderators that also apply to the PCA- 
criminal behavior relation. First, attitudes and behavior show stronger correlations if they are measured at the same level of specificity (correspondence principle; Davidson \& Jaccard, 1979) and if they have the same level of aggregation (aggregation principle; Epstein, 1983). Both specificity and aggregation tend to be low in the case of correlations between PCAs and criminal behavior that typically relate highly aggregated and broad attitude measures to one or a few very specific instances of criminal behavior. Consequently, all psychometric and conceptual problems listed here tend to reduce the correlation between PCAs and reoffending. The observed empirical effect sizes are therefore likely to underestimate the true effect size of PCA-criminal behavior correlations.

\subsubsection{Pro-criminal attitudes related to specific offence types}

In addition to general PCAs, a number of offense-specific PCA measures have been developed. These are attitudes related to sexual offenses (rape and child molestation), battering of women, use and enjoyment of violence, drunk driving (DUI/DWI), and white collar crimes. According to the correspondence principle the correlation between attitudes and behavior increases with increasing content similarity between attitudes and behavior (Davidson \& Jaccard, 1979). One should, therefore, expect that offensespecific PCAs predict the specific criminal behavior in question even better than general PCAs. In the studies reviewed here, Allan, Grace, Rutherford, and Hudson (2007) showed that the Abel Becker Cognitions Scale (assessing distorted cognitions about sex with children) did predict recidivism in sex offenders quite well $(A \cup C=.70)$. In the case of sex offending, recent meta-analyses showed that offense-supportive attitudes are among the robust predictors of sexual recidivism with an effect size of $d=0.22$ (Helmus et al., 2013). Poor victim empathy, however, which may marginally qualify as PCA, was 
not predictive of recidivism ( $d=-0.08$; Mann, Hanson, \& Thornton, 2010). In the present literature review, intervention studies were only found for PCAs related to sexual behavior, use and enjoyment of violence, and drunk driving. The respective measures are listed in Table 2.

(insert Table 2 about here)

\section{Literature search}

The literature research aimed to identify all relevant empirical articles on intervention programs targeting PCAs that were published in English in peer reviewed scientific journals in the last 15 years (after 1996). In a first step, the data bases PsychInfo, Criminal Justice Abstracts, MEDLINE, PubMed, and Web of Science were searched with a conjunction of the keywords pro-criminal (and synonyms), attitudes (and synonyms), intervention (and synonyms), offenders (and synonyms) and the appropriate limitations. The literature search in data bases was accomplished on October 24, 2012. The search was further refined by scrutinizing the references of the already identified articles and standard textbooks in forensic psychology and criminology.

Eventually, the latest volumes and online-first articles of the relevant scientific journals (as defined by having published the articles identified so far) were also scrutinized for relevant journal articles. The initial literature search identified more than 300 articles. Out of these, more than 60 appeared to match the inclusion criteria. Upon closer scrutiny of the articles, those papers were selected that met the following additional criteria: reporting intervention effects on PCAs, evaluating intervention programs that target PCAs and report effects either on PCAs or recidivism, or both. Finally, in the interest of meaningful and robust results all studies with very small 
sample sizes below 40 per group were excluded. The final selection included a total of 24 articles.

\section{Results}

The reviewed 24 studies on intervention effects on general PCAs comprise various intervention programs that range from relatively brief psycho-educational programs (Walters, 2003), cognitive skill programs (Ashford, Wong, \& Sternbach, 2008), resettlement programs (Lewis, Maguire, Raynor, Vanstone, \& Vennard, 2007), to multimodal cognitive-behavioral offender treatment programs such as variants of the Enhanced Thinking Styles (ETS; Tapp, Fellowes, Wallis, Blud, \& Moore, 2009), Reasoning and Rehabilitation (R \& R; Ross \& Fabiano, 1985), and Sex-Offender Treatment Programme (SOTP; Beech et al., 2005) used in the US, Australia, and the UK. All of these programs feature elements targeting PCAs.

The intervention studies reviewed here can be roughly classified into three groups: (1) treatment effects on general or offense-specific PCA measures, (2) treatment effects of programs targeting PCAs on recidivism that do not explicitly measure PCAs, and (3) treatment effects on general or offense-specific PCAs that use recidivism as outcome criterion. Only a few studies have used both PCAs and recidivism as outcome measures and as we will see, often these did not take full advantage of their data sets in directly relating PCA or PCA change to recidivism. With respect to methodological strength most of the studies were based on relatively small effective sample sizes (i.e., offenders with complete measurements of pre-post PCAs or reconviction data). The treatment groups most often have a size between 40 and 100 offenders with more studies on the lower end of this range. Out of 24 studies, only eight feature treatment groups ranging from 200 to 557, and only two impressively large samples of $N>3000$ 
(Barnett, Wakeling, Mandeville-Norden, \& Rakestrow, 2012; Wakeling, Beech, \& Freemantle, 2011).

With respect to study design, out of the 24 studies reviewed, 12 had no control group, and most of the remaining studies used weak control group designs lacking any or adequate empirical evidence that the treatment and control groups were comparable. Consequently, if methodological strength is rated using the Maryland scale (Sherman, Gottfredson, MacKenzie, Eck, Reuter, \& Bushway, 1998), 16 out of 25 relevant studies score 1 or 2 , two score 3 , three 4 , and one 5 (see Tables 3 and 4). We will come back to the implications of the general methodological weakness of this literature.

\subsection{Intervention effects on general pro-criminal attitudes}

In 12 out of 16 relevant studies (Table 3 ) the treatment programs did actually significantly reduce all or some of the PCA measures. By and large, post-pre test differences suggest that PCA-interventions had been successful in almost all relevant studies. Only Hubbard and Pealer (2009) reported a significant increase in PCAs in 7 out of 8 subscales. Notably, the change scores were moderated by depression (more depressed offenders showed stronger PCA change in the wanted direction). However, as illustrated by Figure 1, a significant pre-post design without control group cannot distinguish between PCA program effects (Path B) and similar effects that would have occurred without treatment (Path C).

(insert Table 3 about here)

\subsection{Intervention effects on offence-specific pro-criminal attitudes}

In the five out of eight studies evaluating treatment effects on offense-specific PCAs or recidivism (Table 4), the level of PCAs generally decreased from pre- to post 
treatment scores. Wakeling et al. (2011) did not report attitude change scores, but about a third of the offenders who had participated in the Core or Rolling version of the Sex Offender Treatment Programme evidenced clinically significant change across three sex-related PCA scales. Allan et al. (2007) did not report PCA change scores, but relations between pre-treatment PCAs and recidivism. In the study by Bickley and Beech (2003) with child sex offenders, attitude change was confined to approach-goal offenders, i.e., offenders who held rather positive attitudes toward sex with children. Avoidance goal offenders, who were rather motivated to avoid sex with children, did not show change in PCAs. In the study by Sprang (2008) on attitudes towards drunk driving in intoxicated drivers the treatment group participated in a victim impact panel (VIP) program whereas the control groups only had to pay a fine. Only drivers participating in the VIP showed positive change in their drunk driving related attitudes. Rees-Jones, Gudjonsson, and Young (2012) investigated attitudes towards violence in mentally disturbed offenders. This was the only study using a waiting control group design (Maryland level 4). They reported evidence that treatment and control groups were comparable. Also, the treatment significantly reduced specific PCAs (attitudes towards using and enjoying violence).

(insert Table 4 about here)

\subsection{Treatment effects of pro-criminal attitudes on recidivism}

Five out of eight treatment studies also used recidivism as an outcome criterion of the program. The relation between attitudes and criminal behavior is often not straightforward. This is nicely illustrated in a study by Wright and Mays (1998) that compared recidivism rates of offenders $(N>1900)$ in Oklahoma (USA) who were convicted to serve time in a boot camp, in prison, or were on probation. A subsample of 
boot camp inmates reported surprisingly positive attitudes towards the strict boot camp regimen ( e.g., not less than $80 \%$ reported that they would choose the boot camp program over prison). However, if the recidivism rates were compared, $31 \%$ of the boot camp graduates reoffended, as compared to $13 \%$ of the probationers and $15 \%$ of the prison inmates. The odds ratio for reoffending was 1.5 times higher for the boot camp as compared to prison and probation. It is, of course, possible that exactly those inmates with negative attitudes did reoffend. However, it is not sufficient to simply assume a close relationship between attitudes and reoffending; this link has to be empirically established.

\subsubsection{Intervention studies assessing general pro-criminal attitudes and recidivism} rates

The studies that are potentially most informative for the present review are those which have investigated the effects of treatment programs on PCAs and recidivism. However, surprisingly often the articles lack the results that are necessary to evaluate the effects of treatment-induced PCA change on recidivism rates.

Witte, Di Placido, Gu, and Wong (2006) investigated 60 sex offenders who participated in the Clearwater Sex Offender Treatment Programme and had a postrelease follow-up time of two years. PCAs were assessed using the Criminal Sentiments Scale (CSS). The recidivism rates were $18 \%$ for sexual and violent, $28 \%$ for non-violent, and $38 \%$ for any reconvictions. The treatment produced a significant change in all PCA measures, and both pre-treatment and post-treatment measures of the CSS were correlated to violent and non-violent recidivism (around $r=.30$ ), but not to sexual recidivism. However, the crucial correlation between individual treatment effects on CSS and recidivism was not reported. 
Berman (2004) conducted a similar study investigating the short-term and longterm impact of a Reasoning and Rehabilitation ( $\&$ \& $)$ program with 372 Swedish male prisoners. The treatment yielded significant change in all three CSS subscales (Attitudes Toward the Law, Court, Police; Tolerance for Law Violations; and Identification With Criminal Others). Program completers $(n=281)$ showed a significantly lower reconviction rate than program dropouts $(n=44)$ and a marginally significant effect in comparison to controls $(n=33-45)$. A Cox regression survival analysis revealed that up to 36 months after release the program completers showed a lower recidivism rate than controls, and these a lower recidivism rate than dropouts. However, the paper does not report the critical individual correlations between CSS/CSS change scores and reconviction. Upon request of the authors, Berman kindly provided the results of additional analyses indicating that pre-post change scores of the CSS subscales were not related to recidivism. However, the post-treatment Criminal Identification score from the CSS (as well as the post-treatment impulsivity score) were significantly related to recidivism in a logistic regression analysis. These additional results should be considered preliminary unpublished data that were not peer-reviewed (Berman, personal communication, August 16, 2012).

Wilkinson (2005) investigated the effects of an R \& R program on PCAs (Crime Pics II) and the self-assessed probability of reoffending in a relatively small sample of offenders in London (treatment completers $n=43$, dropouts $n=62$, controls $n=98$ ). The treatment had little effect on reconviction. Paradoxically, when contrasting reoffending and not reoffending program completers, the group of reoffenders showed significantly more PCA change in the desired direction than those who did not recidivate. 


\subsubsection{Intervention studies assessing offence-specific pro-criminal attitudes and} recidivism

Almost all studies including offense-specific PCAs investigated sex offending. The only exception is Sprang (2008) who evaluated a Victim Impact Training scheme for DUI/DWI drivers with a relatively small sample (Treatment $n=103$, Control $n=98$ ). Sprang found significant positive training effects on attitudes toward driving and drinking in the treatment group, and also reduced recidivism rates compared to the control group. However, the relation between individual attitude change and recidivism was not explored.

Three studies investigated the effects of a Sex Offender Treatment Programme run by the Prison Service and the Probation Service in England and Wales (Barnett et al., 2012; Beech, Mandeville-Norden, \& Goodwill, 2012; Wakeling et al., 2011). Among other dynamic risk factors the studies included three offence-specific PCA measures (Entitlement to Sex scale; Hanson, Gizzarelli, \& Scott, 1994; Sex with Children is Justifiable Scale; Mann, Webster, Wakeling, \& Marshall, 2007; Women are Deceitful Scale; NOMS Rehabilitation Services Group, unpublished). Two of these three studies did not use the standard treatment evaluation design to test the effectiveness of an intervention program, but rather the rationale of clinically significant change (Jacobson \& Truax, 1991). In this approach, it is determined whether a treatment did reliably change an outcome variable, and whether the amount of individual change is clinically significant. This is the case if post-treatment scores do not differ from the scores of normal controls.

Beech et al. (2012) studied a sample of 413 sex offenders who participated in a sex offender treatment program run by the Probation Service. Out of these, 135 treatment 
responders were identified who showed evidence of clinically significant change in all three pro-offense attitude scales and in three out of five socio-affective scales. The control group was comprised of a sample of 135 offenders who were not responding to treatment as defined above, and who were matched by offense type and victim type. Although the treatment responders showed a lower absolute rate of reconvictions (9\%) than the control group (15\%), this effect was not statistically significant. About twice as many participants would have been necessary to reach statistical significance for an effect of the size observed.

Wakeling et al. (2011) investigated a large sample $(n=3773)$ of sex offenders who had participated in the Core or Rolling version of the Sex Offender Treatment Programme run by the Prison Service. Due to a lack of norm data for normal controls, clinically significant change was not defined as within the score range of normal controls, but as $\geq 1 S D$ change (based on pre-treatment scores) in the non-deviant direction. Four classes of dynamic risk factors (1) sexual interests, (2) pro-offending attitudes, (3) socio-affective problems, and (4) self-regulation problems were used to define five treatment outcome groups: deteriorated (reliable change in the undesired direction), unchanged, improved (reliable change in the desired direction), recovered (reliable and clinically significant change in the desired direction), and already ok (pretreatment scores in the desirable range). Change scores were aggregated according to the majority of measures within one of the four groups of measures. If the clinical treatment effect status of offenders was dichotomized into the groups change not required and change still required, a positive evaluation in three out of four dynamic risk factors was related to lower recidivism rates (sexual interests, socio-affective problems, and self-regulation problems). However, the status in pro-offending attitudes was not 
related to recidivism. Also, neither the pre-treatment nor the post-treatment scores of the three pro-criminal attitude scores predicted recidivism in ROC analyses.

A similar study with an equally large sample of offenders $(n=3402)$ who had completed the Sex Offender Treatment Programme was conducted by Barnett et al. (2012). Also in this study, neither pre-treatment nor post-treatment scores in sexual offense-specific PCAs were related to recidivism. Only an aggregate individual index of the number of dynamic risk domains scoring above average predicted recidivism.

Given the very large sample sizes examined by Wakeling et al. (2011) and Barnett et al. (2012), the results appear to weigh heavily against the hypothesis that PCAs predict recidivism. However, it has to be noted that both studies used a time at risk frame of two-years as recidivism criterion. The reconviction rates thus were very low with sexual reconviction rates of $1.7 \%$ and $5.4 \%$, and a combined sexual and violent reconviction rate of $4.4 \%$ and $6.9 \%$ in the prison and probation samples, respectively. Given that any single risk factor is expected to show a small to moderate correlation with recidivism, the observed null-effects may simply be due to a floor effect. Moreover, it is questionable whether the inclusion of violent offences is an adequate validation criterion for sexual offence-related PCAs.

Although the data sets of Wakeling et al. (2011) and Barnett et al. (2012) are, to date, the most comprehensive with respect to the quality and integrity of the intervention program, the very large samples, and the use of PCAs and recidivism as outcome measures, the reported data do not answer the crucial questions of this review. Neither the pre- and post-treatment PCA means are reported, nor the correlations between individual PCA difference scores and reoffending. Based on the 
published results it is, therefore, neither possible to fully evaluate the treatment impact on PCAs, nor the relation between individual PCA change and recidivism.

\section{Discussion}

We have reviewed the recent evidence to answer three questions that are critical for the provision of efficient offender treatment programs. In the following sections we present the crucial questions along with the summary of the empirical evidence.

1) How strong is the causal relationship between PCAs and subsequent criminal behavior?

There is a considerable amount of evidence that general and offense-related PCAs correlate weakly to moderately with recidivism. The effect sizes do reach $r \approx .20$ or $d \approx$ 0.20. However, this evidence is mostly based on studies that were conducted to validate PCA scales, or on smaller treatment evaluation studies. This effect does not replicate in the very large British evaluation studies of the Sex Offender Treatment Programme conducted in prison and probation (Barnett et al., 2012, Wakeling et al., 2011). This can be due to the overall very low recidivism rates in these studies, to the much larger (and ecologically valid) heterogeneity of offenders, or other unknown reasons.

2) What interventions have been shown to effectively reduce PCAs?

Almost all treatment studies of cognitive behavioral therapy (CBT)-based and educational offender treatment programs that report treatment effects on PCA scores show that post-treatment scores are significantly lower than pre-treatment scores. However, the overwhelming majority of the studies did not feature adequate control group designs. Therefore, it is not possible to exclude other factors, such as incarceration itself, time, aging, or demand effects as alternative explanations for PCA change. Related to the last point, the validity of PCA self-reports is threatened by 
dissimulation and impression management. Other behavioral outcome measures such as recidivism should therefore be routinely used alongside with measures of PCAs.

3) How effective are treatment programs targeting PCAs to reduce recidivism?

There is considerable evidence that CBT-based offender treatment programs that feature modules targeting general or offense-specific PCAs reduce recidivism. However, the effectiveness of these programs may or may not be related to changing PCAs. In a meta-analysis of CBT-programs that investigated the efficacy of specific program modules, Landenberger and Lipsey (2005) found that the presence of moral reasoning modules was unrelated to treatment success (as indexed by recidivism), and programs featuring victim empathy modules were even negatively related to recidivism. Only a few offender treatment studies used both PCAs and recidivism as outcome measures. There seems to be no published study that reports the relation between individual PCA change and recidivism. In consequence, at present there is no solid empirical evidence in the newer literature that conclusively shows that interventions to reduce general or offense-specific PCAs also reduce recidivism.

\subsection{Strengths and limitations of the evidence}

In the reviewed literature on PCAs, there are at least three strengths. First, a fairly large number of general and offence-specific PCA measures have been developed. This richness is conducive to cover the scope and the structure of possible facets of PCAs in a broad sense. Second, some of these scales have been used repeatedly. This is the case for two scales on general PCAs (variants of the Criminal Sentiments Scale; Reckless, 1967; Rettinger, 1994; Roy, \& Wormith, 1985) and the Crime Pics II scale (Frude, Honess, \& Maguire, 1994). Likewise, for PCAs related to sexual offending two instruments have been repeatedly used: the Cognitive Distortions Scale, Children and Sex Cognitions Scale 
(Beckett, 1987), and the Victim Empathy Distortion Scale (Beckett \& Fisher, 1994).

Cumulative knowledge about PCAs can only build up if the same measures are used across different correctional services and settings. Finally, there are at least two very large and comprehensive studies that could be used to empirically reinvestigate more specific PCA-related questions than those that were in the focus of the originally published reports (Barnett et al., 2012; Wakeling et al., 2011).

However, there are numerous limitations to the existing evidence. As usual in longitudinal studies with offenders, the sample sizes of most studies are too small to have the statistical power to detect the expected weak or at best moderate effects of PCA change on recidivism. An even more critical problem concerns a lack of theoretical rigor. The empirical research on PCA interventions and on the relation between PCAs and recidivism very often does not refer to a clearly formulated causal model of PCAs and recidivism. The overwhelming majority of empirical studies in this review used suboptimal research designs that can maximally produce evidence consistent with the idea that PCAs can be changed by treatment, and that this change reduces recidivism. However, what is required for the commission of efficient offender treatment programs is conclusive evidence that there is a causal link between reducing PCAs and reducing recidivism.

Almost all studies reporting treatment effects on PCAs are lacking adequate control groups. In consequence, it is not possible to infer that a reduction of PCAs was in fact due to the treatment. In a similar vein, most studies that have investigated treatment effects on PCAs and recidivism fail to report the direct relation between individual PCA change and reoffending. In order to identify "psychological meaningful risk factors" (Mann et al., 2010) it is necessary to demonstrate that these are causally 
related to recidivism, and that influencing these risk factors also mitigates recidivism in a theoretical meaningful sense. Empirical research that tries to establish this causal link has to be conducted in a way that confirming (or disconfirming) evidence has a chance to emerge. The literature on PCAs in its present state, however, does not support strong conclusions in either direction.

The most advanced studies reviewed here used multiple logistic regression analyses to investigate how multiple risk factors are related to recidivism. Although this multivariate approach is clearly superior to univariate approaches, it assumes a linear additive model. However, in many cases it is plausible as well that risk factors are not merely additive but also interact with each other. For example, the relation between treatment-induced PCA change and recidivism may depend on offenders' antisociality or psychopathy levels. Such interaction/moderator effects should be investigated in large data sets. In their meta-analysis, Tong and Farrington (2006) found some suggestive evidence that offender age and ethnic background may be important moderators of PCA malleability (i.e., it seems to be more difficult to reduce PCAs in very young, very old, and non-white offenders).

A last important problem concerns the validity of PCA measures that may be jeopardized by demand effects, situational pressures, or trait impression management, particularly in adversarial settings (Mann et al., 2010). Barnett et al. (2012) reported that almost all PCA and other risk factor scales correlated positively with an impression management scale (without reporting the size of these correlations). This finding could indicate that offenders with a high motive for social approval (high social desirability/impression management scores) tend to admit higher PCAs. These findings suggest that it may be worth exploring whether treatment and traits such as impression 
management moderate measures of PCA and other risk factors in a way that blurs the overall positive correlation with recidivism. For example, due to successful treatment some offenders may honestly report lower PCA scores, and others could cease to deliberately fake good, resulting in an apparent increase of PCAs. Both effects could cancel each other out and lead to zero-correlations with recidivism.

\section{Conclusions}

It was the intention of this literature review to evaluate the effectiveness of offender treatment programs to reduce recidivism by reducing PCAs. Unfortunately, the available evidence does not provide a sufficient empirical basis for a best practice recommendation. However, it was possible to derive a number of recommendations how to generate the empirical knowledge that is required to inform and optimize treatment delivery with respect to PCA interventions. In general, treatment effects (preand posttreatment mean scores) of variables related to criminogenic needs should be fully reported, even if results are disappointing. Additionally, future empirical studies should be designed in a way that the causal relations between the specified variables can be tested. In particular, it has to be tested whether a specific PCA treatment influences PCAs (as opposed to no treatment or other treatment elements), and whether PCA change influences recidivism (as opposed to other treatment effects).

To test treatment effects, it is mandatory to include control groups and to make sure that treatment and control groups are comparable. The "gold standard" for such research designs are Randomized Control Trials (RCTs). However, in practice it has proven difficult to implement RCTs for ethical and practical reasons. A more feasible and ethically less problematic alternative would be the use of a dismantling or componentanalysis design. In this approach modular treatment programs are delivered as usual, 
but (almost) all participants skip one randomly selected program module (e.g., a victim empathy module or a module targeting PCAs). Instead of the "missed" module, offenders could participate in a comprehensive assessment session.

This method leads to subsamples of offenders who have not participated in one single module, and these can be contrasted with all other offenders who did. After building up a sufficient sample size this design allows for very strong tests of the impact of every single module on recidivism. The main ethical problem of RCTs to deprive offenders of necessary treatment is very much reduced because each offender participates in the entire treatment except one module. As long as the efficiency of this module is not clearly empirically established, this evaluation strategy appears ethically acceptable.

Furthermore, it seems promising to investigate differential treatment effects. Especially in the large data sets already available to (Barnett et al., 2012; Wakeling et al., 2011) multivariate analyses of treatment effects should include moderator or interaction effects of variables such as ethnical background, age, psychopathy/antisociality, sexual deviance, etc. Thereby, groupings or dichotomizations of continuous measures should be avoided. For example, by splitting an offender sample at the median or mean of some risk variable into the groups "unproblematic" and "problematic", much valuable information is lost and the cut-off is often arbitrary and potentially misleading. Data analytics strategies based on continuous data are almost always more adequate and more informative as they have increased statistical power (e.g., multiple hierarchical regression analyses with moderators included as interaction terms; Cohen, Cohen, West, \& Aiken, 2003). 
In addition to the established self-report measures of PCAs, it appears promising to explore the usefulness of indirect measures. Recently, an indirect (latency-based) priming measure of offense-specific rape attitudes (Widman \& Olson, 2012) has been successfully used to predict the frequency of sexual assault perpetration even after controlling for explicit measures of rape myth acceptance and hostility towards women. Polaschek, Bell, Calvert, and Takarangi (2010) have assessed automatic attitudes toward violence (i.e., an Implicit Association Test with weapons versus entertainment items) in a sample of high risk violent offenders. The Violence-IAT was related to a Violence Risk Scale. As in the case of assessing deviant sexual preferences (Banse, Schmidt, \& Clarbour, 2010), indirect measures of PCAs may complement explicit measures and help to alleviate the problem of dissimulation and demand effects. A second advantage of indirect measures is that they offer the possibility of assessing automatic behavior tendencies that may be highly relevant for offending behavior (Van Gelder, in press). PCAs have so far been analyzed as mere cognitive distortions, illusions, or selfindulgent excuses. However, recent research by Brezina and Topalli (2012) has shown that a large proportion of offenders conceive themselves as successful criminals with a high criminal self-efficacy. These offenders tend to think that criminal behavior is the thing they are really good at, and some may feel that it is the only thing they are good at. They do not regard conviction and incarceration as proof of failure, but rather as a kind of formative feedback, an opportunity to learn and to increase their criminal skills. The notion of criminal self-efficacy goes far beyond the traditional view of PCAs and may be more difficult to change. Current treatment programs should be reviewed to take this new aspect of PCAs into account. 


\section{References}

Abel, G. G., Gore, D. K., Holland, C. L., Camp, N., Becker, J. V., \& Rather, J. (1989). The measurement of the cognitive distortions in child molesters. Annals of Sex Research, 2, 135-153.

Allan, M., Grace, R. C., Rutherford, B., \& Hudson, M. S. (2007). Psychometric assessment of dynamic risk factors for child molesters. Sexual Abuse: A Journal of Research and Treatment, 19, 247-367. doi: 10.1177/107906320701900402

Andrews, D. A., \& Bonta, J. (2010). The psychology of criminal conduct (5th ed.). Mathew Bender \& Co.: New Providence, NJ.

Ashford, J. B., Wong, K. W., \& Sternbach, K. O. (2008). Generic correctional programming for mentally ill offenders: A pilot study. Criminal Justice and Behavior, 35, 457 - 473. doi: 10.1177/0093854807313356

Banse, R., Schmidt, A. F., \& Clarbour, J. (2010). Indirect measures of sexual interest in child sex offenders: A multi-method approach. Criminal Justice and Behavior, 37, 319-335. doi: 10.1177/0093854809357598

Barnett, G. D., Wakeling, H. C., Mandeville-Norden, R., \& Rakestrow, J. (2012). How useful are psychometric scores in predicting recidivism for treated sex offenders? International Journal of Offender Therapy and Comparative Criminology, 56, 420-446. doi: 10.1177/0306624X11403125

Barriga, A. Q., \& Gibbs, J. C. (1996). Measuring cognitive distortions in antisocial youth: Development and preliminary validation of the How I Think Questionnaire. Aggressive Behavior, 22, 333-343. doi: 10.1002/(SICl)10982337(1996)22:5<333::AID-AB2>3.0.CO;2-K

Bäckström, M., \& Björklund, F. (2008). The Measures of Criminal Attitudes and Associates (MCAA): Further testing of structural and criterion-related validity. Criminal Justice and Behavior, 35, 1398-1410. doi: 10.1177/0093854808322239

Beech, A. R. (1998). A psychometric typology of child abusers. International Journal of Offender Therapy and Comparative Criminology, 42, 319-339. doi: $10.1177 / 0306624 \times 9804200405$

Beech , A. R., Mandeville-Norden, R., \& Goodwill, A. (2012). Comparing recidivism rates of treatment responders/nonresponders in a sample of 413 child molesters 
who had completed Community-based sex offender treatment in the United Kingdom. International Journal of Offender Therapy and Comparative Criminology, 56, 29-49. doi: 10.1177/0306624X10387811

Beech, A. R., Oliver, C., Fisher, D., \& Beckett, R. C. (2005). STEP 4: The Sex Offender Treatment Programme in prison: Addressing the offending behaviour of rapists and sexual murderers. London, UK: HM Prisonservice.

Berman, A. H. (2004). The Reasoning and Rehabilitation Program: Assessing short- and long-term outcomes among male swedish prisoners. Journal of Offender Rehabilitation, 40, 85-103. doi: 10.1300/J076v40n01_05

Beckett, R. C. (1987). The children and sex questionnaire. Available from Richard Beckett, Room FF39, The Oxford Clinic, Littlemore Health Centre, Sanford Road, Littlemore, Oxford, OX4 4XN, England.

Beckett, R. C., \& Fisher, D. (1994). Assessing victim empathy: A new measure. Paper presented at the 13th Annual Conference of the Association for the Treatment of Sexual Abusers, San Francisco.

Bickley, J. A., \& Beech, A. R. (2003). Implications for treatment of sexual offenders of the Ward and Hudson Model of Relapse. Sexual Abuse: A Journal of Research and Treatment, 15, 121-134. doi: 10.1177/107906320301500203

Bourgon, G., \& Armstrong, B. (2005). Transferring the principles of effective treatment into a "Real World" prison setting. Criminal Justice and Behavior, 32, 3-25. doi: $10.1177 / 0093854804270618$

Brezina, T., \& Topalli, V. (2012). Criminal self-efficacy: Exploring the correlates and consequences of a "successful criminal" identity. Criminal Justice and Behavior, 39, 1042-1062. doi: 10.1177/0093854812438345

Cohen, J., Cohen, P., West, S. G., \& Aiken, L. S. (2003). Applied multiple regression/correlation analysis for the behavioral sciences $\left(3^{\text {rd }}\right.$ ed.). Mahwah, NJ: Lawrence Erlbaum.

Cullen, A. E., Clarke, A. Y., Kuipers, E., Hodgins, S., Dean, K., \& Fahy, T. (2012). A multisite randomized controlled trial of a cognitive skills programme for male mentally disordered offenders: Social-cognitive outcomes. Psychological Medicine, 42, 557-569. doi: 10.1017/S0033291711001553 
Davidson, A. R., \& Jaccard, J. J. (1979). Variables that moderate the attitude-behavior relation: Results of a longitudinal survey. Journal of Personality and Social Psychology, 37, 1364-1376.Eagly, A. H., \& Chaiken, S. (1993). The psychology of attitudes. Harcourt Brace Jovanovitch College Publishers: Fort Worth.

Epstein, S. (1983). Aggregation and beyond: Some basic issues on the prediction of behavior. Journal of Personality, 51, 360-392. doi:10.1111/j.14676494.1983.tb00338.x

Eysenck, S. B. G., \& Eysenck, H. J. (1978). Impulsiveness and venturesomeness: their position in a dimensional system of personality description. Psychological Reports, 43, 1247-1255.

Festinger, L. (1957). A theory of cognitive dissonance. Evanston, IL: Row, Peterson.

Fox, S., \& Leicht, S. (2005). The association between the offender-victim relationship, severity of offence and attribution of blame in mentally disordered offenders. Psychology, Crime \& Law, 11, 255-264. doi: 10.1080/10683160410001672419

Frude, N., Honess, T., \& Maguire, M. (1994). Crime-Pics /I Manual. Michael and Associates: Cardiff.

Gendreau, P., Grant, B. A., Leipciger, M., \& Collins, C. (1979). Norms and recidivism rates for the MMPI and selected experimental scales on a Canadian delinquent sample. Canadian Journal of Behavioral Science, 11, 21-31. doi: $10.1037 / \mathrm{h} 0081569$

Girad, L. \& Wormith, J. S. (2004). The predictive validity of the Level of Service Inventory-Ontario Revision on general and violent recidivism among various offender groups. Criminal Justice and Behavior, 31, 150-181. doi: $10.1177 / 0093854803261335$

Goldstein, A. P., Glick, B., \& Gibbs, J. (1998). Aggression Replacement Training revised edition: A comprehensive intervention for aggressive youth. Champaign, IL: Research Press.

Gudjonsson, G. H. \& Singh, K. K. (1989). The revised Gudjonsson Blame Attribution Inventory. Personality and Individual Differences , 10, 67-70. 
Hanson, R. K., Gizzarelli, R., \& Scott, H. (1994). The attitudes of incest offenders: Sexual entitlement and acceptance of sex with children. Criminal Justice and Behavior, 21, 187-202. doi: 10.1177/0093854894021002001

Helmus, L., Hanson, K. R., Babchishin, K. M., \& Mann, R. E. (2013). Attitudes supportive of sexual offending predict revidivism: A meta-analysis. Trauma, Violence, \& Abuse, 14, 34-53. doi: 10.1177/1524838012462244

Holliday, S. B., Heilbrun, K. \& Fretz, R. (2012). Examining improvements in criminogenic needs: The risk reduction potential of a structured re-entry program. Behavioral Science and the Law, 30, 431-447. doi: 10.1002/bsl.2016

Hubbard, D. J., \& Pealer, J. (2009). The importance of responsivity factors in predicting reductions in antisocial attitudes and cognitive distortions among adult male offenders. The Prison Journal, 89, 79-98. doi: 10.1177/0032885508329987

Jacobson, N. S., \& Truax, P. (1991). Clinical significance: A statistical approach to defining meaningful change in psychotherapy research. Journal of Consulting and Clinical Psychology, 59, 12-19.

Kroner, D. G., \& Mills, J. F. (2003). Criminal Attribution Inventory (CRAI) manual. Unpublished User's Guide.

Kroner, D. G., \& Mills, J. F. (2004). The Criminal Attribution Inventory: A measure of offender perception. Journal of Offender Rehabilitation, 39, 15-29. doi: 10.1300/J076v39n04_02

Landenberger, N. A., \& Lipsey, M. W. (2005). The positive effects of cognitivebehavioral programs for offenders: A meta-analysis of factors associated with effective treatment. Journal of Experimental Criminology, 1, 451-476. doi: $10.1007 / \mathrm{s} 11292-005-3541-7$

Lewis, S., Maguire, M., Raynor, P., Vanstone, M., \& Vennard, J. (2007). What works in resettlement? Findings from seven Pathfinders for short-term prisoners in England and Wales. Criminology \& Criminal Justice, 7, 33-53. doi: $10.1177 / 1748895807072475$

Mann, R. E., Hanson, R. K., \& Thornton, D. (2010). Assessing risk for sexual recidivism: Some proposals on the nature of psychologically meaningful risk factors. Sexual 
Abuse: A Journal of Research and Treatment, 22, 191-217. doi: $10.1177 / 1079063210366039$

Mann, R. E., Webster, S., Wakeling, H. C., \& Marshall, W. L. (2007). The measurement and influence of child sexual abuse supportive beliefs. Psychology, Crime \& Law, 13, 443-458. doi: 10.1080/10683160601061141

Maruna, S. (2001). Making good: How ex-convicts reform and rebuild their lives. Washington, DC: American Psychological Association Books.

Maruna, S., \& Copes, H. (2005). What have we learned from five decades of neutralization research? Crime and Justice, 32, 221-320.

Maruna, S., \& Mann, R. (2006). A fundamental attribution error: Rethinking cognitive distortions. Legal and Criminological Psychology, 11, 155-177. doi: $10.1348 / 135532506 \times 114608$

McGuire, J., \& Hatcher, R. (2001). Offense-Focused Problem Solving: Preliminary evaluation of a cognitive skill program. Criminal Justice and Behavior, 28, 564587. doi: $10.1177 / 009385480102800502$

Middleton, D., Mandeville-Norden, R., \& Hayes, E. (2009). Does treatment work with Internet sex offenders? Emerging findings from the internet sex offender treatment programme (i-SOTP). Journal of Sexual Aggression, 15, 5-19. doi: $10.1080 / 13552600802673444$

Mills, J. F., Kroner, D. G., \& Forth, A. E. (2002). Measures of Criminal Attitudes and Associates (MCAA): Development, factor structure, reliability, and validity. Assessment, 9, 240-253. doi: 10.1177/1073191102009003003

NOMS Rehabilitation Services Group (unpublished). Women are Deceitful scale. Available from Rehabilitation Services Group, NOMS, 4th Floor, Clive House, 70 Petty France, London SW1H 9EX, UK.

Polaschek, D. L. L., Bell, R. K., Calvert, S. W., \& Takarangi, M. K. T. (2010). Cognitivebehavioural rehabilitation of high-risk violent offenders: Investigating treatment change with explicit and implicit measures of cognition. Applied Cognitive Psychology, 24, 437-449. doi: 10.1002/acp.1688

Reckless, W. C. (1967). The Crime Problem. New York: Appleton Century-Crofts. 
Rees-Jones, A., Gudjonsson, G., \& Young, S. (2012). A multi-site controlled trial of a cognitive skills program for mentally disordered offenders. BMC Psychiatry, 12, Art.No.44.

Rettinger, L. J. (1994). An Overview of the Criminal Sentiments Scale. Ottawa, Canada: Carleton University.

Robinson, D., \& Porporino, F. J. (2001). Programming in cognitive skills: The Reasoning and Rehabilitation Programme. In C. R. Hollin (Ed.), Handbook of offender assessment and treatment (pp. 179-193). Chichester: John Wiley \& Sons.

Rosenbaum, M. (1980). A schedule for assessing self-control behaviours: preliminary findings. Behavior Therapy, 11, 109-121. doi: 10.1016/S0005-7894(80)80040-2

Ross, R., \& Fabiano, E. (1985). Time to think: A cognitive model of delinquency prevention and rehabilitation. Johnson City, TN: Institute of Social Sciences and Arts, Inc.

Ross, R., Fabiano, E., \& Ross, R. (1986/2000). Reasoning and Rehabilitation: A handbook for teaching cognitive skills. Ottawa: T3 Associates.

Roy, R. E., \& Wormith, J. S. (1985). The effects of incarceration: Measuring criminal sentiments (Programs Branch user report). Ottawa: Ministry of the Solicitor General of Canada.

Sherman, L. W., Gottfredson, D. C., MacKenzie, D. L., Eck, J., Reuter, P., \& Bushway, S. D. (1998). Preventing crime: What works, what doesn't, what's promising? Washington D.C.: U.S. Department of Justice, National Institute of Justice.

Shields, I. W., \& Whitehall, G. C. (1991). The Pride in Delinquency Scale. Paper presented at the Eastern Ontario Correctional Psychologists' winter conference, Burritts Rapids, Canada.

Simourd, D. J. (1997). The Criminal Sentiments Scale-Modified and Pride in Delinquency Scale. Criminal Justice and Behavior, 24, 52-70. doi: $10.1177 / 0093854897024001004$

Simourd, D. J., \& Olver, M. E. (2002). The future of criminal attitudes research and practice. Criminal Justice and Behavior, 29, 427-446. doi: $10.1177 / 0093854802029004005$ 
Simourd, D. J. , \& van de Ven, J. (1999). Assessment of criminal attitudes: Criterionrelated validity of the Criminal Sentiments Scale-Modified and Pride in Delinquency Scale. Criminal Justice and Behavior, 26, 90-106. doi: $10.1177 / 0093854899026001005$

Spon, R. (1999). Corrective Thinking treatment manual: Charting a new course curriculum. Retrieved from http://www.truthought.com

Sprang, G. (2008). Victim Impact Panels: An examination of the effectiveness of this program on lowering recidivism and changing offenders attitudes about drinking and driving. Journal of Social Service Research, 22, 73-84. doi: 10.1300/J079v22n03_04

Sykes, G., \& Matza, D. (1957). Techniques of Neutralization: A Theory of Delinquency. American Sociological Review, 22, 664-670.

Tapp, J., Fellowes, E., Wallis, N., Blud, L., \& Moore, E. (2009). An evaluation of the Enhanced Thinking Skills (ETS) programme with mentally disordered offenders in a high security hospital. Legal and Criminological Psychology, 14, 201-212. doi: $10.1348 / 135532508 \times 336178$

Tong, L. S. J. \& Farrington, D. P. (2006). How effective is the "Reasoning and Rehabilitation" programme in reducing reoffending? A meta-analysis of evaluations in four countries. Psychology, Crime \& Law, 12, 3-24. doi:10.1080/10683160512331316253

Van Gelder, J.-L. (in press). Beyond rational choice: The hot/cool perspective of criminal decision making. Psychology, Crime \& Law. doi: $10.1080 / 1068316 X .2012 .660153$

Wakeling, H., Beech, A. R., \& Freemantle, N. (2011). Investigating treatment change and its relation to recidivism in a sample of 3773 sex offenders in the UK. Psychology, Crime \& Law, 1-20 iFirst Article. doi: 10.1080/1068316X.2011.626413

Walker, J. S. (2005). The Maudsley violence questionnaire: Initial validation and reliability. Personality and Individual Differences, 38, 187-201. doi: 10.1016/j.paid.2004.04.001 
Walters, G. D. (1990). The criminal lifestyle: Patterns of serious criminal conduct. Newbury Park, CA: Sage.

Walters, G. D. (1995). The psychological inventory of criminal thinking styles. Part I: Reliability and preliminary validity. Criminal Justice and Behavior, 22, 307-325. doi: $10.1177 / 0093854895022003008$

Walters, G. D. (1998). Changing lives of crime and drugs: Intervening with substanceabusing offenders. Washington, DC: Taylor and Francis.

Walters, G. D. (2000). Outcome expectancies for crime: Their relationship to fear and the negative consequences of criminal involvement. Legal and Criminological Psychology, 5, 261-272. doi: 10.1348/135532500168128

Walters, G. D. (2003). Development of a self-report measure of outcome expectancies for crime. Journal of Offender Rehabilitation, 37, 1-10. doi: 10.1300/J076v37n01_01

Walters, G.D. (2004). Changes in positive and negative crime expectancies in inmates exposed to a brief psychoeducational intervention: further data. Personality and Individual Differences, 37, 505-512. doi: 10.1016/j.paid.2003.09.019

Walters, G. D. (2005). Incremental validity of the Psychological Inventory of Criminal Thinking Styles as a predictor of continuous and dichotomous measures of recidivism. Assessment, 12, 19-27. doi: 10.1177/1073191104270662

Walters, G. D. (2007). Response style versus crime specific cognition: Predicting disciplinary adjustment and recidivism in male and female offenders with the PICTS. Assessment, 14, 35-43. doi: 10.1177/1073191106292957

Walters, G. D. (2011). Taking the next step: Combining incrementally valid indicators to improve recidivism prediction. Assessment, 18, 227-233. doi: $10.1177 / 1073191110397484$

Walters, G. D., Trgovac, M., Rychlec, M., DiFazio, R., \& Olson, J. R. (2002). Assessing change with the psychological inventory of criminal thinking styles: A controlled analysis and multisite cross-validation. Criminal Justice and Behavior, 29, 308331. doi: $10.1177 / 0093854802029003004$ 
Ware, J. \& Mann, R. E. (2012). How should "acceptance of responsibility" be adressed in sexual offending treatment programs? Aggression and Violent Behavior, 17, 279-288. doi: 10.1016/j.avb.2012.02.009

Widman, L., \& Olson, M. (2012). On the relationship between automatic attitudes and self-reported sexual assault in men. Archives of Sexual Behavior; online first on May 232012 as doi: 10.1007/s10508-012-9970-2

Wilkinson, J. (2005). Evaluation evidence for the effectiveness of Reasoning and Rehabilitation Programme. The Howard Journal, 44, 70-85. doi: 10.1111/j.14682311.2005.00356.x

Witte, T. D., Di Placido, C., Gu, D., \& Wong, S. C. P. (2006). An investigation of the validity and reliability of the Criminal Sentiments Scale in a sample of treated sex offenders. Sexual Abuse: A Journal of Research and Treatment, 18, 249-258. doi: $10.1177 / 107906320601800303$

Wright, D. T., \& Mays, L. (1998). Correctional Boot Camps, attitudes, and recidivism: The Oklahoma experience. Journal of Offender Rehabilitation, 28, 71-87. doi: 10.1300/J076v28n01_05

Young, S., Chick, K. \& Gudjonsson, G. (2010). A preliminary evaluation of reasoning and rehabilitation 2 in mentally disordered offenders ( $R$ \& R2M) across two secure forensic settings in the United Kingdom. Journal of Forensic Psychiatry \& Psychology, 21, 336-349.

Young, S. J., \& Ross, R. R. (2007). R\&R2 for youths and adults with mental health problems: A prosocial competence training program. Ottawa, ON: Cognitive Centre of Canada. doi: 10.1080/14789940903513203 
Table 1. General pro-criminal attitude scales in this review.

\begin{tabular}{|c|c|c|}
\hline Scale & Subscales & Paper* \\
\hline $\begin{array}{l}\text { Blame Attribution Inventory (BAl; } \\
\text { Gudjonsson \& Singh, 1989) }\end{array}$ & $\begin{array}{l}\text { Guilt attributions }(\alpha=.83) \text {, external attributions }(\alpha=.71) \text {, and mental element attributions }(\alpha=.83) \text { (Fox \& } \\
\text { Leicht, 2005) }\end{array}$ & 5,8 \\
\hline $\begin{array}{l}\text { Crime Pics II (Frude, Honess, \& Maguire, } \\
\text { 1994) }\end{array}$ & $\begin{array}{l}\text { General attitude to offending, anticipation of reoffending, victim hurt denial ( } \alpha \geq .73 \text { ), evaluation of crime } \\
\text { as worthwhile }(\alpha=.55) \text { (cf. McGuire \& Hatcher, 2001) }\end{array}$ & $\begin{array}{l}5,9,10, \\
14\end{array}$ \\
\hline $\begin{array}{l}\text { Criminal Attribution Inventory (CRAI; } \\
\text { Kroner \& Mills, 2004) }\end{array}$ & $\begin{array}{l}\text { Psychopathology }(\alpha=.71) \text {, Personal }(\alpha=.62) \text {, Victim }(\alpha=.65) \text {, Alcohol }(\alpha=.84) \text {, Society }(\alpha=.62) \text {, Randomness } \\
(\alpha=.55)\end{array}$ & 8 \\
\hline $\begin{array}{l}\text { Criminal Sentiments Scale (CSS; CSS-M, } \\
\text { Simourd, 1997) }\end{array}$ & $\begin{array}{l}\text { CSS: Attitudes Toward the Law (ATL), Court, Police, Tolerance for Law Violations (TLV), and Identification } \\
\text { With Criminal Others (ICO); ( } \alpha=.94) \text { (Witte, Di Placido, Gu \& Wong, 2006) } \\
\text { The first three subscales are combined to form the Law-Courts-Police (LCP) Scale; CSS-M ( } \alpha=.91 \text {; } \\
\text { subscales } \alpha=.51-.87 \text { ) (Simourd \& Olver, 2002) }\end{array}$ & $\begin{array}{l}1,3,4, \\
15\end{array}$ \\
\hline $\begin{array}{l}\text { How I Think Questionnaire (HIT; Barriga \& } \\
\text { Gibbs, 1996) }\end{array}$ & $\begin{array}{l}\text { Cognitive distortions: Self-centeredness, blaming others, minimizing/mislabeling, assuming the worst; } \\
\text { Behavioral referents: Opposition/Defiance, Physical Aggression, Lying, and Stealing ( subscales: .78 } \leq \alpha \leq \\
.90) \text {; Aggregate measures: Overt Scale, Covert Scale, Total score }(\alpha=.96)\end{array}$ & 7 \\
\hline $\begin{array}{l}\text { Level of Service Inventory-Ontario Revision } \\
\text { (LSI-OR) }\end{array}$ & $\begin{array}{l}\text { General Risk/Need }(\alpha=.91) \text { : Criminal History, Employment/Education, Peers, Leisure/Recreation, } \\
\text { Family/Marital, Criminal Orientation/ Attitude, Substance Abuse, and Antisocial Pattern (subscales: } .32 \leq \alpha \\
\leq .80) ; \text { Specific Risk/Need }(\alpha=.62): \text { Personal Problems with Criminogenic Potential, History of Perpetration } \\
\text { (Girad \& Wormith, 2004) }\end{array}$ & 4 \\
\hline $\begin{array}{l}\text { Level of Service/Case Management } \\
\text { Inventory (LS/CMI) }\end{array}$ & Procriminal Attitude/Orientation & 6 \\
\hline $\begin{array}{l}\text { Measures of Criminal Attitudes and } \\
\text { Associates (MCAA; Mills, Kroner, \& Forth, } \\
\text { 2002) }\end{array}$ & $\begin{array}{l}\text { MCAA total }(\alpha=.90) \text {, Violence }(\alpha=.80) \text {, Antisocial Intent }(\alpha=.84) \text {, Entitlement }(\alpha=.63) \text {, Associates ( } \alpha \\
=.82) \text {. }\end{array}$ & 2 \\
\hline Outcome Expectancies for Crime (OEC) & OEC-Positive score $(\alpha=.91)$, OEC-Negative score $(\alpha=.75)$ (Walters, 2003) & 12 \\
\hline Pride in Delinquency & Shame versus pride about criminal behavior $(\alpha=.75)$ (Simourd, 1997) & 1 \\
\hline $\begin{array}{l}\text { Psychological Inventory of Criminal } \\
\text { Thinking Styles (PICTS; Walters, 2005, 2007) }\end{array}$ & $\begin{array}{l}\text { Mollification }(\alpha=.64) \text {, Cutoff }(\alpha=.78) \text {, Entitlement }(\alpha=.59) \text {, Power Orientation }(\alpha=.65) \text {, Sentimentality ( } \\
\alpha=.55) \text {, Superoptimism }(\alpha=.63) \text {, Cognitive Indolence }(\alpha=.76) \text {, and Discontinuity }(\alpha=.79) \text { (Walters, 2005) }\end{array}$ & 11,13 \\
\hline
\end{tabular}

Note. ${ }^{*}$ The numbers correspond to the number of the paper in the research summary overview in Table 3. 
Table 2. Offence-specific pro-criminal attitude scales in this review.

\begin{tabular}{|c|c|c|}
\hline Scale & Subscales & Paper* \\
\hline $\begin{array}{l}\text { Abel-Becker Cognitions Scale (ABCS; } \\
\text { Abel, Gore, Holland, Camp, Becker, } \\
\text { \& Rather, 1989) }\end{array}$ & Total score (6 factor-based scales $.59 \leq \alpha \leq .84$ ) & 17 \\
\hline $\begin{array}{l}\text { Attitudes/Intentions Toward } \\
\text { Drinking and Driving }\end{array}$ & $\begin{array}{l}\text { Attitude Towards Drinking and Driving, Intention to Continue Drinking and Driving, Consequences, Fairness of } \\
\text { DWI Laws }\left(r_{\mathrm{tt}}=.81\right)(\text { Sprang, 2008) }\end{array}$ & 23 \\
\hline $\begin{array}{l}\text { Cognitive Distortions Scale, Children } \\
\text { and Sex Cognitions Scale }\end{array}$ & $\begin{array}{l}\text { Cognitive Distortions Scale, Emotional Empathy with Children Scale }(\alpha=.90) \text { (cf. Beech, Mandeville-Norden, \& } \\
\text { Goodwill, 2012) }\end{array}$ & $\begin{array}{c}18,19, \\
20\end{array}$ \\
\hline $\begin{array}{l}\text { Maudsley Violence Questionnaire } \\
\text { (Walker, 2005) }\end{array}$ & Machismo $\left(\alpha_{\hat{\delta}}=.91, \alpha_{+}=.86\right)$, Acceptance $\left(\alpha_{\hat{\delta}}=.76, \alpha_{+}=.73\right)$ [consistency measures in a student population] & 16 \\
\hline $\begin{array}{l}\text { Sex with Children is Justifiable } \\
\text { (Mann, Webster, Wakeling, \& } \\
\text { Marshall, 2007) }\end{array}$ & Total score $(\alpha=.94)$ & 24 \\
\hline The Entitlement to Sex scale & Total score $(\alpha=.65)$ (cf. Wakeling, Beech, Freemantle, 2011) & 24 \\
\hline Victim Empathy Distortion Scale & Total score $(\alpha=.89)$ (cf. Beech, 1998) & $\begin{array}{l}19,20, \\
21\end{array}$ \\
\hline Women are Deceitful scale & Total score $(\alpha=.79)$ (cf. Wakeling, Beech, Freemantle, 2011) & 24 \\
\hline
\end{tabular}

Note. ${ }^{*}$ The numbers correspond to the number of the paper of the research summary overview in Table 4. 
Table 3. Studies on general pro-criminal attitudes included in this review.

\begin{tabular}{|c|c|c|c|c|c|}
\hline & References & $\begin{array}{l}\text { Sample } \\
\text { size }\end{array}$ & $\begin{array}{l}\text { Maryl } \\
\text { and } \\
\text { rating }\end{array}$ & $\begin{array}{l}\text { Program/ } \\
\text { intervention }\end{array}$ & Treatment effects \\
\hline 1. & $\begin{array}{l}\text { Ashford, Wong, \& } \\
\text { Sternbach (2008) }\end{array}$ & $\begin{array}{l}\mathrm{T}_{\mathrm{IT}}=47 \\
\mathrm{~T}_{\mathrm{C}}=24 \\
\mathrm{~T}_{\mathrm{NC}}=23 \\
\mathrm{C}_{\mathrm{tau}}=29\end{array}$ & 2 & $\begin{array}{l}\text { MCSTAR } \\
\text { program } \\
\rightarrow \text { including } \\
\text { cognitive } \\
\text { skills training } \\
\text { that } \\
\text { targeted } \\
\text { criminogenic } \\
\text { attitudes }\end{array}$ & $\begin{array}{l}\text { Treatment changes in expected direction } \\
\text { - Criminal Sentiments Scale-Modified (CSS-M; Simourd, 1997) except IOC subscale } \\
\text { No treatment change } \\
\text { - total score Pride in Delinquency (PID; Shields \& Whitehall, 1991) } \\
\text { - CSS-M-IOC subscale } \\
\text { Group differences } \\
\text { Reoffenders } \\
\text { significant differences in the mean change scores for CSS-M-ICO subscale }\end{array}$ \\
\hline 2. & $\begin{array}{l}\text { Bäckström, \& } \\
\text { Björklund (2008) }\end{array}$ & $\begin{array}{l}\mathrm{T}_{\mathrm{IT}}=184 \\
\mathrm{~T}_{\mathrm{C}}=80 \\
\mathrm{~T}_{\mathrm{NC}}=104 \\
\mathrm{C}_{\mathrm{NO}}=556\end{array}$ & 2 & $\begin{array}{l}\text { Cognitive } \\
\text { Skills (Ross } \\
\text { \& Fabiano, } \\
\text { 1985) } \\
\text { Aggression } \\
\text { Replacemen } \\
\text { t Training } \\
\text { (Goldstein, } \\
\text { Glick, \& } \\
\text { Gibbs, 1998) }\end{array}$ & $\begin{array}{l}\text { Treatment changes in expected direction } \\
3 \text { of } 4 \text { subscales of the Measures of Criminal Attitudes and Associates (MCAA) [Entitlement, } \\
\text { Violence, Antisocial Intent] } \\
\text { No treatment change } \\
\text { Antisocial Intent subscale of the MCAA } \\
\text { Group differences } \\
\text { pretest scores: } T_{C} \text { Vs. } T_{N C}, \text { n.s. } \\
\text { MCAA: } T_{I T}>C \\
\text { Testscores are meaningfully related to criminal history variables }\end{array}$ \\
\hline 3. & Berman (2004). & $\begin{array}{l}T_{I T}=372 \\
T_{C}=286 \\
C=451\end{array}$ & 4 & $\begin{array}{l}\text { Reasoning } \\
\text { and } \\
\text { Rehabilitatio } \\
\text { n Program } \\
\text { (Robinson \& } \\
\text { Porporino, } \\
\text { 2001; Ross, } \\
\text { Fabiano \& } \\
\text { Ross, }\end{array}$ & $\begin{array}{l}\text { Pro-social short-term improvements for } \\
\text {-Criminal Sentiments Scale (CSS; Gendreau, Grant, Leipciger, \& Collins, 1979) } \\
\text { Attitudes towards the law, courts, police(ALCP), Tolerance of law violation (TLV), Identification with } \\
\text { Criminal Others (IOC) } \\
\text { Long Term } \\
\text {-risk of reconviction (up to } 36 \text { months): } \mathrm{T}_{\mathrm{C}}<\mathrm{T}_{\mathrm{NC}} \\
-36 \text {-month reconviction rates: } \\
48 \% \text { program completers, } 60.3 \% \text { controls, } 73.4 \% \text { dropouts } \\
\text { Personal communication: }\end{array}$ \\
\hline
\end{tabular}


4. Bourgon \& $\quad \mathrm{T}_{\mathrm{TT}}=482$ Amstrong (2005) $\quad \mathrm{T}_{\mathrm{C}}=408$

$\mathrm{T}_{\mathrm{NC}}=74$

$C=138$

5. Cullen, Clarke, Kuipers, Hodgins,

Dean, \& Fahy

(2012)

$\mathrm{T}_{\mathrm{TT}}=44$

$\mathrm{T}_{\mathrm{C}}=22$

$\mathrm{T}_{\mathrm{NC}}=22$

$\mathrm{C}_{\mathrm{tau}}=40$
Holliday,
$\mathrm{T}_{\mathrm{IT}}=94$
Heilbrun,
$\mathrm{T}_{\mathrm{C}}=71$

(2012)

$\mathrm{T}_{\mathrm{NC}}=23$
$1986 / 2000)$

Structured

cognitive

behavioral/c

orrectional

treatment

programs

$[5,10$ or 15

weeks]

5

Reasoning

and

Rehabilitatio

n (R\&R)

programme
- CSS subscale criminal identification and the Eysenck (1987) impulsivity scale posttreatment predicted reconviction

- significantly less recidivism in $\mathrm{T}_{C}(31.1 \%)$ than Controls $(41.3 \%) \rightarrow X^{2}(1, N=620)=5.00, p<.05$ with an effect size $r=.10$.

reduction in recidivism per week of treatment (statistically controlling for risk and needs) was 1.7\% - significant role of dosage (odds ratios between .92 and .95 per week of treatment; adjusted effect sizes ( $r$ ) of .01 and .02)

\section{Pretreatment - end of treatment changes}

Intention to treat group and completers alone

Treatment as usual

- No statistically significant changes on any of the subscales

Pretreatment - 12-month after treatment assessments

Completers

Improvements for the Crime Pics II (Frude, Honess, \& Maguire, 1994) General attitude

subscale, anticipation of reoffending subscale, and Evaluation of crime as worthwhile subscale Treatment as usual (TAU)

- $\quad$ statistically significant improvements on the anticipation of reoffending scale of the CrimePics II

-Linear regression analyses demonstrated a significant effect of treatment group on change scores on external attribution scale of Blame Attribution Inventory

Completers vs. controls

Linear regression analyses detected a significant effect of program completion, relative to TAU, on change scores on two of the Crime Pics II subscales (general attitude and evaluation of crime as worthwhile)

- Significant improvements for Procriminal Attitudes/orientation: $M=0.48$ (SD=0.98), $r^{2}=0.19$

- Changes for participants with highest level of need:

Procriminal Attitudes/orientation: $M=1.40(S D=0.84), r^{2}=0.75$

rational

emotive

behavior

therapy

(REBT) 
7. Hubbard, \& Pealer (2009)

$\mathrm{T}_{\mathrm{C}}=257$

8. Kroner, \& Mills (2004)

2

\section{Corrective}

Thinking

curriculum

developed

by Spon

(1999)

Study 1: no

treatment,

one-month

test-retest

Study 2:

sexual

offender

program

Study 3:

violent

offender

treatment

program

Study 4:

substance

abuse

program \&

living skills

program

Study 5:

25 sessions

treatment to

replace pro-

criminal

beliefs
How I Think Questionnaire (Barriga \& Gibbs, 1996): significant differences between the pre- and posttests; post-treatment scores changed significantly in the undesired direction for all subscales except for minimizing.

Study 2

Significant change between pre- and post-score only for the scales Alcohol and Victim of Criminal Attribution Inventory (CRAl; Kroner \& Mills, 2003)

No change for the scales Personality, Psychopathology, Attribution of Crime to Random of the CRAI.

Victim, Alcohol, Randomness (CRAI) were positive correlated with external Blame scale of the Blame Attribution Inventory (BAl; Gudjonsson \& Singh, 1989)

Study 3

Significant change between pre- and post-scores only for the scales Alcohol, Victim, Random Scale of the CRAI

Study 4

Pre-post-Score alcohol treatment: The Alcohol Blame Scale score of the CRAI reduces (effect size $d=$ .40)

Pre-post-scale living skill program: Psychopathology Blame Scale score of the CRAI reduces significantly

Study 5

Only the Alcohol Blame Scale reduces significantly (small effect size) 
9. Lewis, Maguire, Raynor,

Vanstone, \& Vennard (2007)

10. McGuire, \& Hatcher (2001)

11. Tapp, Fellowes, $\quad \mathrm{T}_{\mathrm{C}}=62$ Wallis, Blud, \& $\quad \mathrm{T}_{\mathrm{NC}}=21$ Moore (2009)

12. Walters, G.D. (2004)

pre- and

post-

scores of

PICS II

were

available]

$\mathrm{T}_{\mathrm{C}}=220$
$\mathrm{T}_{\mathrm{C}}=454^{*}$

[*prisoners

for which

treatment

the CRIME-

Offense-

Focused

problem-

solving

training

2

The

Enhanced

Thinking

Skills (ETS)

training

course

$\begin{array}{lll}\mathrm{T}_{\mathrm{C}}=45 & 2 & \text { Lifestyle } \\ \text { [participati } & & \begin{array}{l}\text { Issues } \\ \text { (Walters, }\end{array} \\ \text { on to } & & \text { 1990, 1998) } \\ \text { waiting list } & & \end{array}$

measure,

pre-

treatment

and post-

treatment

measure]

\section{Treatment change}

-number of positive changes in both attitudes and self-reported problems, and the total mean changes across all projects are statistically significant $(p<.01)$

\section{Group differences}

Greater level of attitude change for CRIME-PICS II (Frude, et al., 1994)

- among prisoners in the probation-led schemes than in the voluntary sector-led schemes ( $p$

$<.01$, male prisons only)

- $\quad$ among FOR program attendees than other prisoners $(p<.01)$

- among prisoners experiencing 'high activity in custody' (defined as five or more types of action) than among those experiencing 'low activity in custody' (two or fewer types of action) $(p<.01)$

Pre- and post-Test correlations

All significant for Crime PICS II Questionnaire (Frude, et al., 1994)

Pre- and Post-Test differences

Significant changes for - Crime PICS II Questionnaire for the scales General attitudes to offending,

Anticipation of reoffending, Victim hurt denial

Treatment change

\section{Completers}

- significant differences for pre- and post-scores on four of the eight scales of the

Psychological Inventory of Criminal Thinking Styles (Walters, 1995):

Mollification, Cut-Off, Power Orientation, and Cognitive Indolence

- no significant improvement post-intervention on subscales of the PICTS that related to perspective-taking, particularly regarding the impact of offending (on self and others)

\section{Pre-Post treatment change}

- significant pre-post-increase on Outcome Expectancies for Crime Negative (OEC-NEG) Scale - no significant decrease for anticipated positive outcomes (Outcome Expectancies for Crime Positive Scale; OEC-POS)

OEC-POS with 12 anticipated positive outcomes and four anticipated negative outcomes (OEC-NEG) (Walters 2000, 2003).

Waiting list - pre-test change:

Waiting list - pre-test (fell short of significant)

- Increase OEC-POS

- Decrease OEC-NEG 
13. Walters, Trgovac, Study 1: Rychlec, DiFazio, $\quad \mathrm{T}_{\text {IT }}=98$ \& Olson (2002) $\quad T_{C}=85$

\section{$\mathrm{C}=35$}

Study 2:

$\mathrm{T}_{\text {TT }}=80$

Study 3:

$\mathrm{T}_{\text {IT }}=110$

(85 from

study 1

and 25

from study

2)

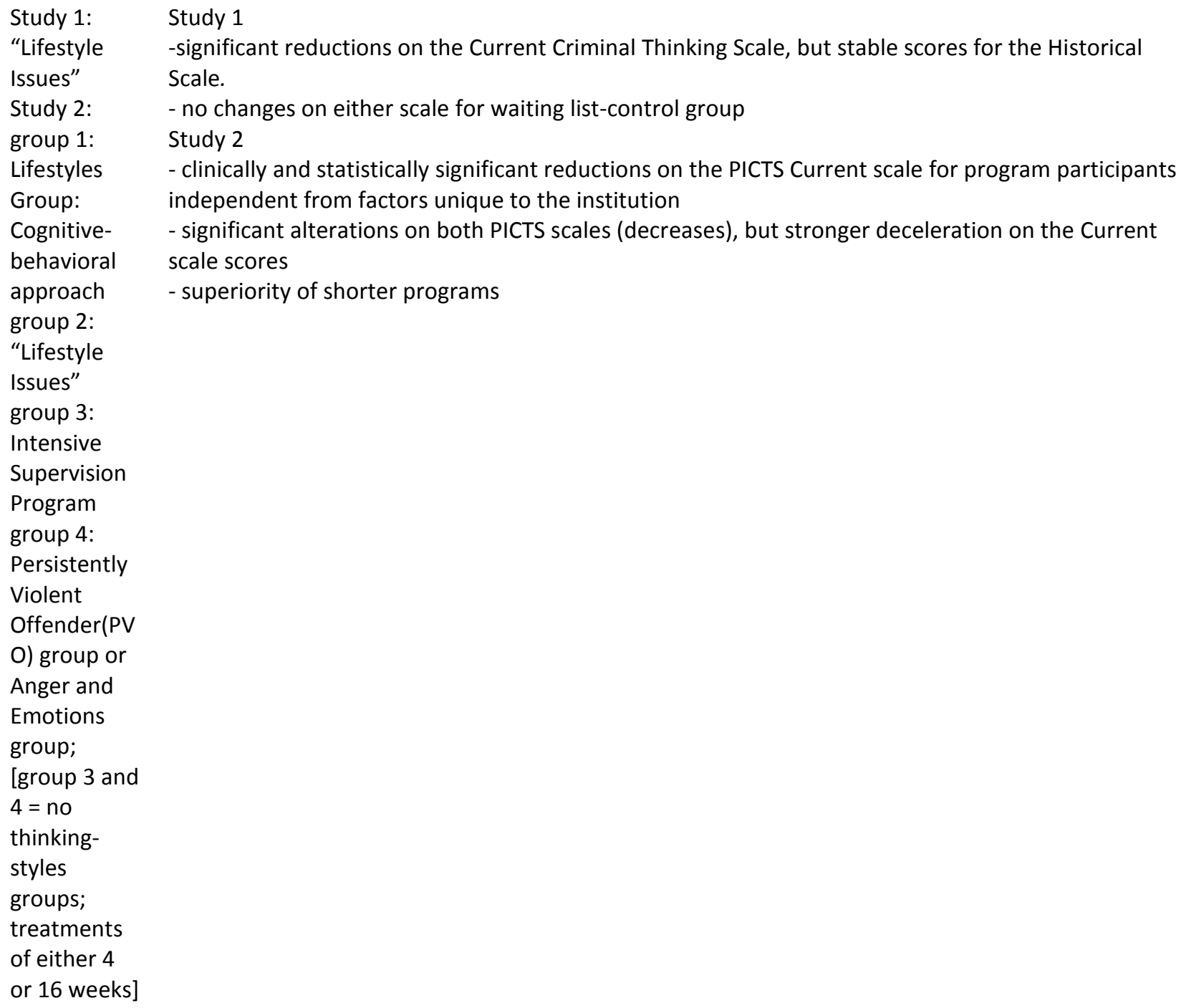


14. Wilkinson (2005)

$$
\begin{aligned}
& T_{\text {IT }}=105 \\
& T_{C}=43 \\
& T_{N C}=62 \\
& C=98
\end{aligned}
$$

15. Witte, Di Placido, $\mathrm{T}_{\mathrm{C}}=72$ Gu, \& Wong

(2006)

16. Young, Chick, \&
Gudjonsson (2010)

$$
\begin{aligned}
& \mathrm{T}^{*}=58 \\
& \mathrm{~T}_{\mathrm{TT}}=34 \\
& \mathrm{~T}_{\mathrm{C}}=22 \\
& \mathrm{~T}_{\mathrm{NC}}=12= \\
& \mathrm{C}_{1} \\
& \mathrm{C}_{2}=12 \\
& \text { (waiting } \\
& \text { list) }
\end{aligned}
$$

Reasoning
and

and

Rehabilitatio

n (Ross, \&

Fabiano,

1985)

2

Clearwater
Sex Offender
Treatment

Program
Reconviction (2yrs after intervention)

- $\quad$ no difference in reconviction between offenders ( $R \& R$ and controls)

- $\quad$ program completers were less likely to be reconvicted than controls

\section{Attitude change pre-post-treatment}

- reconvicted Offenders: Revise likelihood of reoffending down

- not reconvicted Offenders: revised self-assessment upwards, almost no change in Crimepics score(Criminality: Crime Pics Scale; Frude, Honess \& Magurie, 1994), reported to be less selfcontrolled (Self-control; Rosenbaum, 1980), small downward shift in self-reported problems

-> offenders whose attitude changes pro-social were more likely to be reconvicted than offenders whose attitude didn't changed positive

Pre-post-treatment change

the Criminal Sentiments Scale scores for two of three subscales (CSS; Gendreau, Grant,

Leipciger, \& Collins, 1979) changed significantly in the predicted direction

- no significant differences were observable for the ICO (Identification with Criminal Others) subscale of the CSS

$\underline{\text { Reconviction and CSS scores }}$

- CSS pre- and post-treatment total scores and subscale scores predict general recidivism (violent and non-violent), but not sexual-reoffending

- CSS pre-treatment total score and subscale scores were more strongly correlated with prior violent than with prior non-violent convictions and minimally with prior sexual convictions

2 Reasoning Pre-post-treatment change:
Completers

and

Rehabilitatio

$n$ for

Mentally

Offenders

(R\&R2M);

Young and
- $\quad$ significant improvement on measures relating to attitude Maudsley Violence Questionnaire (MVQ; Walker, 2005)

Waiting list controls

- $\quad$ no significant differences found between Time 1 and 2 
Table 4. Studies investigating intervention effects on offence-specific pro-criminal attitudes or recidivism

\begin{tabular}{|c|c|c|c|c|c|}
\hline & References & $\begin{array}{l}\text { Sample } \\
\text { size }\end{array}$ & $\begin{array}{l}\text { Maryl } \\
\text { and } \\
\text { rating }\end{array}$ & $\begin{array}{l}\text { Program/ } \\
\text { intervention }\end{array}$ & Treatment effects \\
\hline 17. & $\begin{array}{l}\text { Allan, Grace, } \\
\text { Rutherford, \& } \\
\text { Hudson (2007) }\end{array}$ & $\begin{array}{l}\mathrm{T}_{\text {IT }}=557 \\
\mathrm{~T}_{\mathrm{C}}=495 \\
\mathrm{~T}_{\mathrm{NC}}=62\end{array}$ & 1 & $\begin{array}{l}\text { Cognitive- } \\
\text { behavioral } \\
\text { treatment } \\
\text { program for adult } \\
\text { men }\end{array}$ & $\begin{array}{l}\text { Recidivism } \\
\text { Sexual offense } 49(9.9 \%) \\
\text { Violent offense } 48(9.3 \%) \text { general offense } 81(15.7 \%) \\
\text { AUC values were significantly greater than chance }(.50) \text { for all factors, with Pro- } \\
\text { Offending Attitudes (AUC=0.70) having a strong relationship to reoffending }\end{array}$ \\
\hline 18. & $\begin{array}{l}\text { Barnett, } \\
\text { Wakeling, } \\
\text { Mandeville- } \\
\text { Norden, \& } \\
\text { Rakestrow (2012) }\end{array}$ & $\begin{array}{l}\mathrm{T}_{\mathrm{IT}}=3,402 \\
\mathrm{~T}_{\mathrm{NC}}=175\end{array}$ & $n / a$ & $\begin{array}{l}\text { One of three U.K. } \\
\text { accredited sexual } \\
\text { offender } \\
\text { treatment } \\
\text { programs: } \\
\text { - Community Sex } \\
\text { Offender } \\
\text { Groupwork } \\
\text { Program (C- } \\
\text { SOGP) } \\
\text { - Thames Valley } \\
\text { Sex Offender } \\
\text { Groupwork } \\
\text { Program (TV- } \\
\text { SOGP) } \\
\text { - Northumbria } \\
\text { Sex Offender } \\
\text { Groupwork } \\
\text { Program (N- } \\
\text { SOGP) }\end{array}$ & $\begin{array}{l}\text { None of the pretreatment scores from offence-supportive-attitudes measures were } \\
\text { predictors for recidivism outcome. } \\
\text { None of the post-treatment scores from offence-supportive-attitudes measures } \\
\text { were predictors for recidivism outcome. }\end{array}$ \\
\hline
\end{tabular}


19. Beech, Mandeville-

Norden, \&

Goodwill (2012)

20. Bickley \& Beech (2003)

$$
\begin{aligned}
& \mathrm{T}_{\text {IT }}=413 \\
& \mathrm{~T}_{\mathrm{NC}}=\mathrm{C}= \\
& 135
\end{aligned}
$$

(n)

\section{One of three U.K. accredited sexual offender \\ treatment \\ programs:}

- Community Sex

Offender

Groupwork

Program (C-

SOGP)

- Thames Valley

Sex Offender

Groupwork

Program (TV-

SOGP)

- Northumbria

Sex Offender

Groupwork

Program (N-

SOGP)

$\mathrm{T}_{\mathrm{C}}=59$
divided in
approach
$\left(\mathrm{T}_{\text {app }}=44\right)$
and
avoidant
$\left(\mathrm{T}_{\text {av }}=15\right)$
goals
regarding
deviant
sexual
activity
with

Intensive

cognitive-

behavioral

program

$\rightarrow$ change of

attitudes and

beliefs regarding

sex with children

\section{Treatment change}

Post-treatment 135 participants fall within the non-offender range of responding for the three of the offense-related/pro-offending measures

- Cognitive Distortions Scale (Children and Sex Questionnaire; Beckett, 1987)

- Emotional Identification with Children Scale (Children and Sex Questionnaire;

\section{Beckett,1987)}

- Victim Empathy Distortions Scale (Beckett \& Fisher, 1994)

Recidivism

$12 \%$ (51 offenders) of the sample had recidivated within 2 to 4 years, 44 had been reconvicted for a sexually related offense

\section{Group differences}

Significant smaller proportion of responders recidivated compared to 135 non-

responders (matched to the responder group), indicating a $40 \%$ reduction in

recidivism in the responder-group (effect size of difference .18).

\section{Pre/Post-intervention change data}

- Cognitive Distortions Scales (Beckett, 1987): Changes in approach, not in avoidant group

- Victim Empathy Distortion Scale (Beckett \& Fisher, 1994): Changes in approach, not

in avoidant group

Group differences

Offenders vs. controls

- Levels of Cognitive Distortions and Victim Empathy Distortions: $T_{\text {app }}>C$

- Levels of Cognitive Distortions and Victim Empathy Distortions: $T_{a v}<C$ 
children

\section{$\mathrm{C}_{\mathrm{NO}}=81$}

21. Middleton, $\quad \mathrm{T}_{\mathrm{C}}=264$ Mandeville-

Norden, \& Hayes, (2009).

Gudjonsson, \&

Young (2012)

$\mathrm{T}_{\mathrm{IT}}=67$

$\mathrm{T}_{\mathrm{C}}=52$

$C=54$

23. Sprang (2008)

$\mathrm{T}_{\mathrm{C}}=103$

$\mathrm{C}=75$
3

Internet sex

offender

treatment

programme (i-

SOTP)

4

Reasoning \&

Rehabilitation

Mental Health

program (R\&R2

$\mathrm{MHP}$ )

Victim Impact

Panel

24. Wakeling, Beech, $T_{C}=3773$

2 \& Freemantle (2011).

\section{Pre-post-treatment change}

Significant improvement in deficits concerning socio-affective functioning and a

decrease in PCAs (Victim Empathy Distortions (Beckett \& Fisher, 1994) and Cognitive

Distortions (Children and Sex Questionnaire; Beckett, 1987)

No change for Emotional Congruence (Children and Sex Questionnaire; Beckett,

1987)

Comparison $\mathrm{T}_{\mathrm{C}}$ and $\mathrm{C}$ post-treatment

-significant less violent attitudes measured by MVQ for total score and subscales

(Cohen's d total score: $d=.24, p<.01$ ) in T ${ }^{\prime}$ 's than Controls

Comparison $\mathrm{T}_{\mathrm{C}}$ and $\mathrm{C}$ at three-month follow-up

-significant less violent attitudes measured by MVQ for total score and subscales

(Cohen's d total score: $d=.23, p<.01$ ) in Tc's than Controls

Pre-post-treatment change

Victim Impact Panel attendees

- reported significant less to continue drinking and driving

- showed a significant change in attitude towards drinking and driving in expected direction

- showed a significant change in consideration of consequences in expected direction - no changes in attitudes regarding fairness of drinking while intoxicated laws

Controls

- no significant changes for all measures

Recidivism (12-month following post-test data collection)

9.3\% for $T_{c} ; 18.7 \%$ for Controls; significant difference

Treatment-change and recidivism- Change in (sex offence-related) PCAs was not significant
Cognitive

Behavioral

Treatment

Programmes:

- Core

programme (high-

risk male sexual

offenders) 
programme

(lower risk male

sexual offenders)

Note. $\mathrm{T}_{\mathrm{IT}}=$ Intention to Treat; $\mathrm{T}_{\mathrm{C}}=$ Treatment Completers; $\mathrm{T}_{\mathrm{NC}}=$ Non-Completers; $\mathrm{C}=$ Control Group; $\mathrm{PCAs}=$ pro-criminal attitudes 


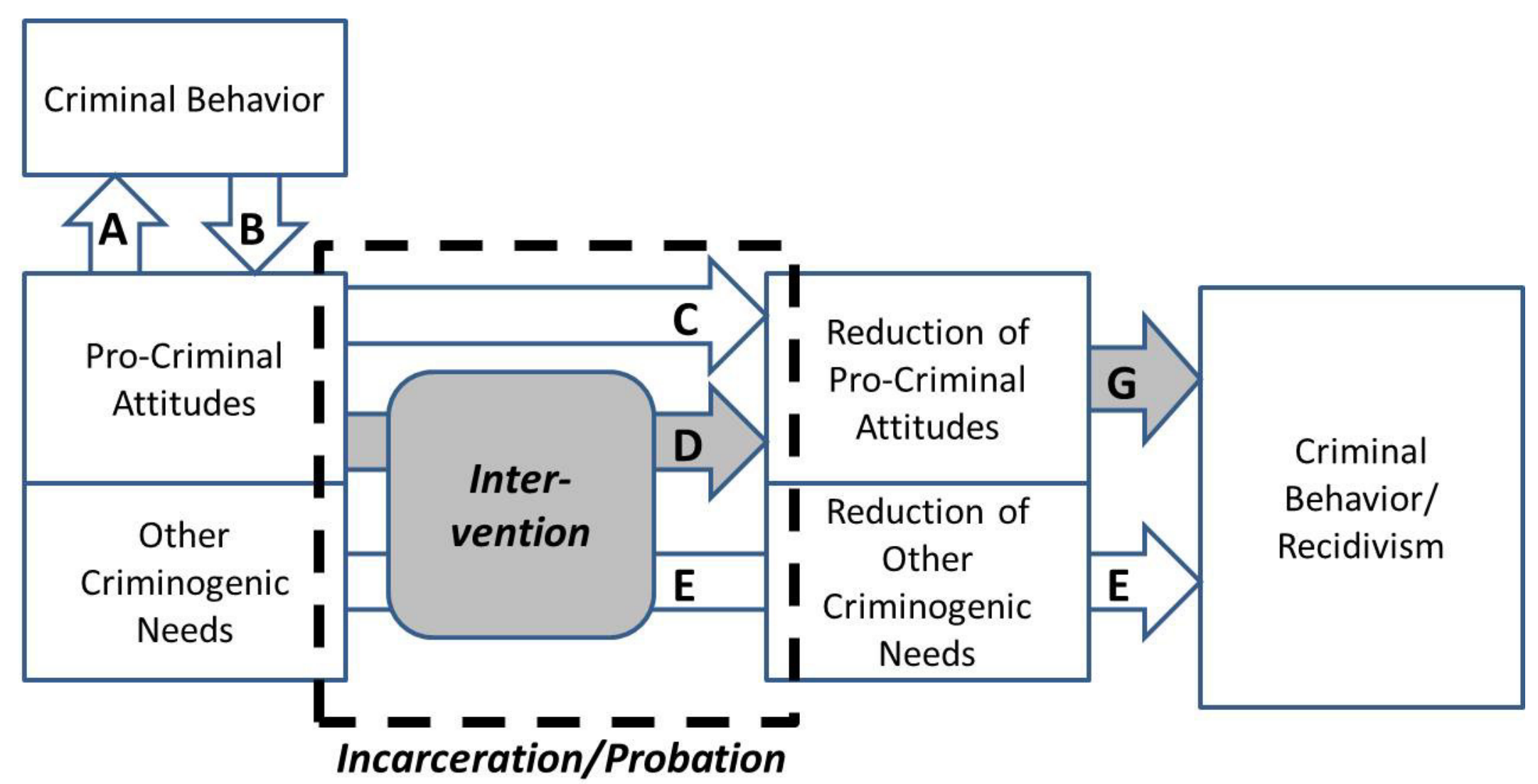

Figure 1. A causal path model of pro-criminal attitudes, intervention, and criminal behavior 